\title{
Engajamento e Protagonismo Estudantil na Promoção da Educação Médica em Tempos de Pandemia da Covid-19
}

\section{Students' Engagement and Protagonism in the Promotion of Medical Education During the Covid-19 Pandemic}

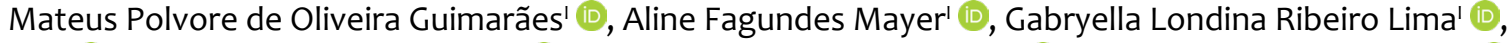

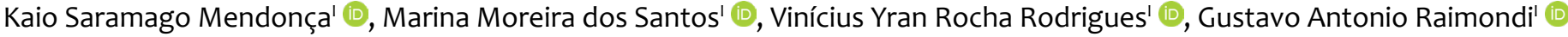

\section{RESUMO}

Introdução: Este artigo relata as experiências da representação estudantil da Faculdade de Medicina de uma universidade federal brasileira, incluindo organização de eventos, participação nas decisões em instâncias superiores e interrupção do ensino em uma pandemia.

Relato de Experiência: Inicialmente, houve a mobilização do movimento estudantil para regulamentar as atividades remotas. Em seguida, outras instituições da universidade movimentaram-se para regulamentar as atividades acadêmicas remotas emergenciais. Por fim, realizou-se um evento para informar aos estudantes os planos para a implementação dessas atividades e dialogar sobre questões da educação médica nesse contexto.

Discussão: A importância da integração das instituições de representação estudantil com órgãos superiores é notável e ocorre pela proatividade $\operatorname{dos}($ as) alunos(as) e pelo consenso com docentes e técnicos(as) administrativos(as). Foi preciso considerar o contexto socioeconômico dos envolvidos e manejar seus interesses. Assim, lidar com conflitos e propor soluções abrangentes foi fundamental para garantir, de forma democrática, condições viáveis para aplicação das atividades acadêmicas remotas emergenciais por meio da promoção da inclusão digital para professores(as). Além disso, criaram-se meios de assistências para os(as) estudantes. Portanto, percebeu-se o protagonismo dos(as) acadêmicos(as) na resolução de conflitos por meio da participação ativa em conselhos e realização de eventos informativos e consultivos destinados ao restante da comunidade, o que resultou também em pesquisa, extensão e atividades para a melhora da saúde mental no contexto atual.

Conclusão: Percebe-se que a participação acadêmica nas deliberações da universidade possibilitou decisões mais democráticas que consideraram os impactos da pandemia na vida dos(as) estudantes e as futuras consequências na formação médica. Além disso, esse processo despertou o interesse da comunidade em atividades de gestão acadêmica.

Palavras-chave: Educação Médica; Isolamento Social; Pandemia.

\section{ABSTRACT}

Introduction: This article reports on the experiences of student representation at the medical school of a Brazilian federal university, including organizing events, participating in decisions at higher levels and interrupting teaching during a pandemic.

Experience Report: Initially, the students' movement was mobilized to regulate remote activities. Then other university institutions took action to regulate Emergency Remote Academic Activities. Finally, an event was held to inform students about plans for the implementation of these activities and to discuss medical education issues in this context.

Discussion: The importance of the integration of student representation institutions with higher bodies is remarkable and occurs due to the students' proactivity and the consensus with teaching staff and administrative technicians. It was necessary to consider the socio-economic context of those involved and manage their interests. Therefore dealing with conflicts and proposing comprehensive solutions was fundamental in order to guarantee viable conditions for the democratic application of Emergency Remote Academic Activities, promoting digital inclusion for teachers and creating means of student assistance. Hence, it became clear that academics were playing a pivotal role in conflict resolution through active participation in councils and holding informative and consultative events for the rest of the community, which also promoted research, community outreach projects and activities to improve mental health in the current setting.

Conclusion: It can be seen that academic participation in university deliberations enabled more democratic decisions that considered the impacts of the pandemic on the lives of students and its future consequences on medical training. It furthermore sparked community interest in academic management activities.

Keywords: Medical Education; Social Isolation; Pandemic

'Universidade Federal de Uberlândia, Uberlândia, Minas Gerais, Brasil.

Correspondência:

Mateus Polvore de Oliveira Guimarães.

Campus Umuarama, Bloco 2U, Sala 08, Avenida Pará, nº 1720, Bairro Umuarama, Uberlândia, MG, Brasil. CEP: 38405-320.

E-mail: mateuspolvore@hotmail.com

Recebido em 11/08/20; Aceito em 09/09/20. 


\section{INTRODUÇÃO}

Recentemente a Organização Mundial da Saúde declarou a pandemia da coronavirus disease 2019 (Covid-19)' Por conta da alta transmissibilidade da síndrome respiratória aguda grave do coronavírus 2 (severe acute respiratory syndrome coronavirus 2 - Sars-(oV-2), nações inteiras adotaram medidas de confinamento social com profundos impactos socioeconômicos mundiais ${ }^{1,2}$. Nesse ínterim, métodos baseados no ensino a distância (EaD), ferramenta importante na difusão de conhecimento, têm sido propostos e apresentado resultados positivos para o ensino remoto (ER)/ as atividades acadêmicas remotas emergenciais (AARE) ${ }^{2}$.

A literatura e as ferramentas disponíveis para o EaD são vastas e o tema tampouco é novidade, mas requer habilidades e competências relacionadas à tecnologia, a fim de potencializar o processo pedagógico do ER ${ }^{3}$. As AARE, nomenclatura dada pela Universidade Federal de Uberlândia (UFU), como as demais aplicações de ER, criam um período de adaptação para docentes e discentes ao novo método proposto de ensinoz. Desse modo, os órgãos de representatividade estudantil da UFU, como diretórios acadêmicos e o Diretório Central dos Estudantes (DCE), engajados na democratização do ensino por meio de pautas como as condições mínimas para acesso às aulas daqueles com dificuldades socioeconômicas fizeram múltiplos apontamentos para melhor aplicação das medidas a distância.

Muito se tem debatido sobre as experiências dos(as) estudantes e as respostas deles(as) ao ER, e, consequentemente, sobre os efetivos resultados 3 . Fatores como menor comprometimento de tempo, alta taxa de retenção, soluções de prática on-line de questões, sala de aula invertida e teleconferências são debatidos ${ }^{3,4}$, mas também deve existir espaço para temáticas como a saúde dos(as) estudantes e as atividades acadêmicas de pesquisa e extensão em andamento. Entretanto, a prática do ER não é comumente utilizada nos cursos superiores e programas relacionados à saúde no Brasil, no que concerne aos treinamentos clínico e social e às habilidades manuais, que são intrínsecas à prática ${ }^{4,5}$.

Desse modo, com base na demanda dos(as) discentes apresentada aos seus órgãos representativos, bem como na utilidade das atividades acadêmicas durante o período de isolamento, foi elaborada uma carta propositiva, organizada pelas representações estudantis da universidade, com o objetivo de discutir as atividades remotas, e propôsse a realização de um congresso on-line a fim de debater, disseminar e consolidar as temáticas relacionadas ao ER. Assim, o presente relato de experiência buscará apresentar e analisar criticamente essas atividades na perspectiva da representatividade estudantil e da responsabilidade social em relação aos(às) discentes e docentes de um curso de
Medicina e aos órgãos superiores administrativos de uma universidade pública.

\section{RELATO DE EXPERIÊNCIA}

Ao longo do primeiro semestre de 2020, universidades de diversas partes do país discutiram sobre estratégias de implementação do ER. Na UFU, esse debate começou no início do mês de junho, com mobilização estudantil para estabelecer planos viáveis que incluíram demandas dos(as) alunos(as). Com isso, o DCE, em parceria com os diretórios e centros acadêmicos dos cursos da graduação, elaborou uma carta que abordou desde a necessidade de criar meios para inclusão digital de professores(as) até a importância de prover auxílio aos(às) discentes com acesso precário à internet.

A carta, direcionada ao Conselho de Graduação, era dividida de forma a estabelecer medidas em três momentos diferentes. Em curto prazo, seria necessária a regulamentação de atividades extracurriculares, pesquisas, extensão e trabalhos de conclusão de curso (TCC). Em médio prazo, a universidade deveria preparar a estrutura necessária para as atividades acadêmicas, como aulas on-line, promover a inclusão digital de professores(as) e implementar políticas de assistência estudantil que fornecessem as ferramentas necessárias para a adesão dos(as) discentes. Por fim, seriam analisadas as opções de modelos de atividades remotas com ênfase na importância de não obrigatoriedade em sua participação.

Ainda no mesmo mês, o Conselho de Graduação da UFU formulou a minuta da resolução que dispõe sobre recomendações para AARE, que sugeriu um modelo de caráter não obrigatório, tanto para discentes quanto para docentes, e que começou a delinear um plano detalhado de como essas atividades efetivamente aconteceriam, em consonância com as demandas antes estabelecidas pelo movimento estudantil e de acordo com as normativas nacionais vigentes.

Assim, durante os meses de junho ejulho, representantes de diversas instituições da universidade construíram, de forma conjunta, propostas que originaram a resolução que atualmente regulamenta as AARE. Simultaneamente, estabeleceu-se o Programa Institucional Emergencial de Inclusão Digital, com o objetivo de conceder auxílio de inclusão digital para estudantes economicamente vulneráveis.

Diante dessa realidade e da demanda dos(as) discentes, organizou-se um simpósio on-line com o tema "Educação Médica e Isolamento Social”. O evento foi idealizado e executado por cinco estudantes e supervisionado por um docente. Em um mês, a organização do evento foi realizada por meio de reuniões on-line e por aplicativo de mensagens. Contamos com a colaboração e presença de diversas instituições da nossa faculdade: o diretório acadêmico (DA), 
o Programa de Educação Tutorial (PET), o comitê local da Federação Internacional das Associações dos Estudantes de Medicina do Brasil (International Federation of Medical Students' Association of Brazil - IFMSA Brazil) e a Atlética. A realização se deu em três dias, separados em uma semana, no período da noite, com duração de uma hora e meia cada sessão.

No primeiro dia, contamos com a presença do diretor da Faculdade de Medicina e da coordenadora do curso de Medicina para tratar do tema "Gestão acadêmica durante a pandemia", abordar aspectos sobre como garantir um ensino de qualidade e a saúde $\operatorname{dos}(a s)$ educandos(as) e educadores(as), e apresentar as medidas que estão sendo tomadas pela universidade para implementação do ER. Também esteve presente uma estudante que cursa o estágio supervisionado obrigatório em regime de internato para relatar a experiência dos(as) estudantes no estágio obrigatório, que continuou ocorrendo.

No segundo dia, em que se abordou o tema "Ensino médico e a saúde do estudante durante a pandemia", estiveram presentes: a pró-reitora de Assistência Estudantil da UFU, que teve a fala orientada às ferramentas de apoio estudantil oferecidas pela universidade nesse momento; a presidenta da Atlética, que apresentou as ações de incentivo à atividade física que a instituição está realizando por meio das redes sociais; uma psicóloga do projeto "Proteger-se", núcleo de saúde mental da universidade; e um docente do curso de Medicina que falou sobre a utilização das tecnologias da informação e comunicação (TIC) na educação médica.

Por fim, no último dia, debatemos sobre a importância da "Pesquisa e extensão na graduação durante a pandemia", assim como sobre as ferramentas e estratégias para sua realização durante o isolamento social. Participaram do debate três docentes e um acadêmico que realizam, neste período de pandemia, atividades de pesquisa e extensão e que relataram suas experiências. Para complementar as informações levantadas, a comissão elaborou um material acerca das bolsas de financiamento universitário que continuam sendo oferecidas durante a pandemia, material que foi divulgado para os(as) discentes por meio de grupos em aplicativo de mensagem.

Os(as) palestrantes foram alocados em uma sala na plataforma Conferência Web, com transmissão ao público pelo serviço de streaming da própria Rede Nacional de Ensino e Pesquisa (RNP). Após cada dia, realizamos um feedback com os(as) palestrantes e enviamos um formulário por e-mail aos(às) participantes, que também foi utilizado para contabilizar a presença no evento. No final da semana, realizamos um feedback interno da comissão organizadora.

O evento teve um total de 241 inscritos, dos quais 221 eram da UFU. A grande maioria dos inscritos era de discentes (231, 95,85\%); e os demais, docentes. Os períodos da graduação com maior número de inscritos foram segundo (38), terceiro (36) e sétimo (30). Em relação aos três dias de evento, estiveram presentes 100 pessoas no primeiro dia, 106 no segundo e 83 no terceiro. Os feedbacks quanto à compreensão e ao conteúdo dos três dias do evento, bem como da didática dos apresentadores, foram extremamente positivos. A avaliação do evento como um todo também foi muito positiva.

\section{DISCUSSÃO}

O isolamento social adotado em resposta à pandemia trouxe desafios para a educação médica. Com isso, de forma emergencial, várias escolas médicas deliberaram e executaram modelos de ER. Na UFU, os(as) estudantes de Medicina participaram ativamente dessa deliberação a partir do envolvimento com o DCE e com outras instituições da universidade, o que demonstra a importância dos(as) estudantes e de seu protagonismo sobre o próprio processo de aprendizagem. Isso é fundamental especialmente neste período de crise, em que os inúmeros desafios e as adequações para as atividades a distância podem impactar o projeto pedagógico, assim como cumprimento das Diretrizes Curriculares Nacionais (DCN) 6 .

Diante disso, é de suma importância que professores(as), técnicos(as) administrativos(as) e estudantes estejam envolvidos(as)nos processos de decisão do ensino preconizado na sua universidade, pois essas decisões, somadas ao contexto de isolamento social, afetam diretamente todos(as). Por isso, espaços de debate sobre a educação médica durante a pandemia são essenciais, a fim de compreender as decisões da gestão universitária e as diferentes possibilidades de realizar ensino, pesquisa e extensão. Isso, aliado à preocupação em relação à saúde de educandos(as) e educadores(as), motivou a união de estudantes de diferentes entidades estudantis da Medicina na organização do evento "Educação Médica no Isolamento Social”. Essa ação é um exemplo claro de protagonismo estudantil, a partir da participação e organização dos(as) estudantes no âmbito das instituições de ensino. A atuação dos(as) discentes é essencial na formação de profissionais críticos(as) e conscientes de que devem exercer transformação social, especialmente tendo em vista o dinamismo das mudanças sociais e científicas presentes no contexto atual, que afetam diretamente o cuidado e a formação dos(as) trabalhadores(as) da saúde?

Com a pandemia, o(a) estudante de Medicina, do primeiro ao décimo segundo período do curso, está inserido(a) em vários cenários diferentes. Esses contextos se resumem em suspensão das aulas, redirecionamento do ensino presencial 
para o remoto e antecipação da formatura ${ }^{6}$. No internato médico, por exemplo, o(a) estudante é erroneamente visto(a) como força de trabalho. Mesmo na fase final da graduação, esses(as) discentes ainda necessitam de acompanhamento incessante do(a) preceptor(a) e, quando inseridos(as) nos sistemas de saúde, precisam ter acesso a equipamento de proteção individual (EPI), cuja demanda aumentou durante a pandemia $^{8}$. Diante dessas inúmeras possibilidades, o evento proporcionou a discussão entre gestores(as), docentes e discentes de vários períodos sobre a gestão acadêmica, trazendo esclarecimentos sobre a interface saúde-educação e a compreensão da atual conjuntura.

Mesmo que a infecção por Sars-CoV-2 tenha a potencialidade de atingir todas as pessoas de um país sem fazer distinção de classe social ou raça/cor ou gênero/sexualidade, as desigualdades sociais já existentes explicitam os grupos sociais mais vulneráveis no contexto de pandemia. Ao analisarem esse aspecto nos Estados Unidos, Metzl, Maybank et al. ${ }^{9}$ constataram que a distribuição de mortes causadas por esse patógeno está relacionada aos seguintes fatores: moradia, educação, emprego e assistência médica. O cenário de pandemia descortina problemas sociais já existentes, e isso também deve ser levado em consideração, já que o ineditismo deste momento mostra a complexidade em relação ao oferecimento do ER, o que envolve problemas que vão além do acesso às tecnologias ${ }^{10}$. Por isso, é relevante que os(as) estudantes universitários entendam a gestão estudantil e as ações propostas na sua instituição, pois assim é possível compreender como os desafios se instalam e como as oportunidades de superação/aprendizado podem ser bem aproveitadas.

Como a necessidade de auxílio no tempo de pandemia por Sars-CoV-2 ultrapassa os muros universitários, são imprescindíveis políticas públicas que possam incrementar a infraestrutura, as tecnologias e a alimentação ${ }^{10}$. Ciente disso, a gestão universitária, ao analisar as possibilidades para o ER, além da falta de motivação, habilidades com a tecnologia e não adequação a todas as unidades curriculares, deve considerar o acesso limitado à internet e a computadores ${ }^{11}$. Tempos de calamidade exigem auxílios continuados e implementados. Por isso, o evento, além de esclarecer os(as) estudantes e os(as) professores(as) sobre as bolsas estudantis, que foram remodeladas durante o isolamento social, teve como objetivo informar sobre os auxílios fornecidos em conjunto com a proposta de ER emergencial.

Somados aos desafios estruturais, a ansiedade, o medo e as emoções desordenadas também estão inseridas na vida $\operatorname{dos}\left(\right.$ as) estudantes ${ }^{12}$. Com isso, o evento buscou trazer representantes institucionais para debater sobre a saúde mental no período de isolamento, além de apresentar as possíveis atividades que visam ao bem-estar físico e mental dos(as) discentes de Medicina. Ademais, outra das consequências do isolamento social é um maior tempo livre para os(as) estudantes. Esse tempo pode ser investido em saúde física e mental ou até mesmo em hobbies ${ }^{13}$.

No evento, foram apresentadas outras duas possibilidades de atividades neste tempo de isolamento: pesquisa e extensão. A pesquisa tem um papel relevante na formação, por ensinar habilidades tradicionalmente ausentes no currículo médico, mas importantes para uma carreira fundamentada em Medicina Baseada em Evidências ${ }^{14}$. Já as práticas de extensão, articulando pesquisa e ensino, possibilitam o contato de docentes e estudantes com a comunidade, fazendo cumprir o compromisso da escola médica com a comunidade e promovendo um ambiente adequado de aprendizagem ${ }^{15}$. Utilizar esse tempo para a pesquisa e a extensão reforça o que está nas DCN, em relação à formação integral do estudante de Medicina, articulando ensino, pesquisa e extensão ${ }^{16}$.

\section{CONCLUSÃO}

Depois da pandemia, não sabemos como ficará a nova força do trabalho médico no Brasil. As incertezas estão relacionadas com o desafio de unir a formação médica com o isolamento social, o que vaialém da discussão do ER emergencial e alcança assuntos como antecipação da formatura, situação dos internos, responsabilidade social das escolas médicas em tempos de excepcionalidade e cumprimento das DCN.

Diante desse tempo de incertezas, são de suma importância o engajamento e o protagonismo estudantis nas áreas de gestão universitária, saúde mental e atividades de ensino, pesquisa e extensão dentro da educação médica, a fim de possibilitar a realização de atividades acadêmicas mesmo em tempo de isolamento social.

Nesse contexto, a execução de eventos informativos com representação estudantil é uma forma de apresentar aos(às) discentes alternativas acadêmicas, para que possam despender tempo livre e ainda enriquecer o currículo e a formação como profissionais críticos(as), reflexivos(as) e humanistas. Além disso, é fundamental enfatizar o protagonismo estudantil dos(as) representantes estudantis nas decisões tomadas pelas universidades e informar tais decisões aos(às) estudantes a fim de demonstrar apoio em um momento de angústias diversas.

É importante também discutir o impacto que a aplicação de atividades remotas tem nos educandos(as) e educadores(as), considerando as possibilidades de acesso à informação desse público e fornecer formas de estruturar, de forma democrática, esse meio de ensino, de modo a garantir educação de qualidade e inclusão digital. 


\section{CONTRIBUIÇÃO DOS AUTORES}

Mateus Polvore de Oliveira Guimarães participou da elaboração do manuscrito, da consulta da literatura, da formatação, da revisão e da submissão do artigo. Aline Fagundes Mayer participou da elaboração do manuscrito, da consulta da literatura e da revisão do artigo. Gabryella Londina Ribeiro Lima participou da elaboração do manuscrito, da consulta da literatura, da formatação e da revisão do artigo. Kaio Saramago Mendonça participou da elaboração do manuscrito, da consulta da literatura e da formatação. Marina Moreira dos Santos participou da elaboração do manuscrito, da tradução do resumo, da formatação e da revisão do artigo. Vinícius Yran Rocha Rodrigues participou da elaboração do manuscrito, da tradução do resumo, da formatação e da revisão do artigo. Gustavo Antonio Raimondi participou da orientação para elaboração do manuscrito, da revisão e da correção do artigo.

\section{CONFLITO DE INTERESSES}

Os autores declaram não haver conflito de interesses neste relato.

\section{REFERÊNCIAS}

1. Uddin M, Mustafa F, Rizvi T, Loney $\mathrm{T}$, Al Suwaidi $\mathrm{H}$, Al-Marzouqi A, et al. SARS-CoV-2/COVID-19: viral genomics, epidemiology, vaccines, and therapeutic interventions. Viruses. 2020;12(5):526 [acesso em 2 ago 2020]. Disponível em: https://pubmed.ncbi.nlm.nih.gov/32397688/.

2. Machado Júnior A, Pauna H. Distance learning and telemedicine in the area of Otorhinolaryngology: lessons in times of pandemic. Braz J Otorhinolaryngol. 2020;86(3):271-2 [acesso em 5 ago 2020]. Disponível em: https://www.ncbi.nlm.nih.gov/pmc/articles/PMC7135734/.

3. Almanar MA. The shifting of face to face learning to distance learning during the pandemic Covid-19. Globish: An English-Indonesian Journal for English, Education, and Culture. 2020;9(2)1-8 [acesso em 5 ago 2020]. Disponível em: http://jurnal.umt.ac.id/index.php/globish/article/ view/2772/pdf.

4. Chick R, Clifton G, Peace K, Propper B, Hale D, Alseidi A, et al. Using technology to maintain the education of residents during the COVID-19 pandemic. J Surg Educ. 2020;77(4):729-32 [acesso em 5 ago 2020]. Disponível em: https:// www.sciencedirect.com/science/article/pii/S1931720420300842.
5. Peloso R, Ferruzzi F, Mori A, Camacho D, Franzin L, Teston AM, et al. Notes from the field: concerns of health-related higher education students in Brazil pertaining to distance learning during the Coronavirus pandemic. Eval Health Prof. 2020;43(3):201-3 [acesso em 5 ago 2020]. Disponível em: https://journals.sagepub.com/doi/full/10.1177/0163278720939302.

6. de Oliveira SS, Postal EA, Afonso DH. As escolas médicas e os desafios da formação médica diante da epidemia brasileira da COVID-19: das (in)certezas acadêmicas ao compromisso social. APS em Revista. 2020;2(1):56-60. doi: 10.14295/aps.v2i1.69.

7. Conselho Nacional de Saúde. Resolução $n^{\circ} 569$, de 8 de dezembro de 2017. Diário Oficial da União; 2018 [acesso em 11 ago 2020]. Disponível em: https://conselho.saude.gov.br/resolucoes/2017/Res0569.pdf.

8. Fontanelle LF, Brandão DJ, Sarti TD. Should medical students keep their clinical activities during the COVID-19 pandemic? Rev Bras Educ Med. 2020;44(3):e079. doi: 10.1590/1981-5271v44.3-20200100.

9. Metzl JM, Maybank A, De Maio F. Responding to the COVID-19 pandemic: the need for a structurally competent health care system. JAMA. 2020;324(3):231-2. doi: 10.1001/ jama.2020.9289.

10. Arruda PA. Educação remota emergencial: elementos para políticas públicas na educação brasileira em tempos de COVID-19. EmRede: Revista de Educação a Distância. 2020;7(1):257-75 [acesso em 5 ago 2020]. Disponível em: https://www.aunirede.org.br/revista/index.php/ emrede/article/view/621.

11. Regimi K, Jones L. A systematic review of the factores - enablers and barriers - affecting e-learning in health sciences education. BMC Med Educ. 2020; 20(91):1-18. doi: 10.1186/s12909-020-02007-6.

12. Blasco PG, Benedetto MAC, Levites MR, Moreto G, Janaudis MA. Humanism and medical education in time of COVID-19. Revista de Medicina. 2020;99(2):1-6. doi: 10.11606/issn.1679-9836.v9gi2pi-vi.

13. Chinelatto LA, Costa TR, Medeiros VMB, Boog GHP, Hojaij FC, Tempski $\mathrm{PZ}$, et al. What you gain and what you lose in covid-19: perception of medical students on their education. Clinics (São Paulo). 2020;75:e2133. doi: 10.6061/clinics/2020/e2133.

14. Schexnayder S, Starring H, Fury M, Mora A, Leonardi C, Dasa V. The formation of a medical student research committee and its impact on involvement in departmental research. Med Educ Online. 2018;23(1):1424449. doi: 10.1080/10872981.2018.1424449.

15. Bulcão LG. O ensino médico e os novos cenários de ensino-aprendizagem. Rev Bras Educ Med. 2020;28(1):61-72. doi: 10.1590/1981-5271v28.1-009.

16. Brasil. Resolução $n^{\circ} 3$, de 20 de junho de 2014. Diretrizes Curriculares Nacionais do Curso de Graduação em Medicina. Brasília: Ministério da Educação; 2014 [acesso em 4 ago 2020]. Disponível em: http://portal.mec. gov.br/index.php?option=com_docman\&view=download\&alias=15874rces003-14\&category_slug=junho-2014-pdf\&Itemid=30192. 